\title{
BMJ Open Multicomponent intervention to reduce daily sedentary time: a randomised controlled trial
}

\author{
Lucas J Carr, ${ }^{1}$ Kristina Karvinen, ${ }^{2}$ Mallory Peavler, ${ }^{3}$ Rebecca Smith, ${ }^{3}$ \\ Kayla Cangelosi ${ }^{3}$
}

To cite: Carr LJ, Karvinen K, Peavler M, et al.

Multicomponent intervention to reduce daily sedentary time: a randomised controlled trial. BMJ Open 2013;3: e003261. doi:10.1136/ bmjopen-2013-003261

- Prepublication history for this paper is available online. To view these files please visit the journal online (http://dx.doi.org/10.1136/ bmjopen-2013-003261).

Received 20 May 2013 Revised 12 August 2013 Accepted 29 August 2013

\footnotetext{
${ }^{1}$ Department of Health and Human Physiology, University of lowa, lowa City, Iowa, USA

${ }^{2}$ School of Physical and Health Education, Nipissing University, North Bay, Ontario, Canada

${ }^{3}$ Department of Kinesiology, East Carolina University, Greenville, North Carolina, USA
}

Correspondence to Dr Lucas J Carr; Lucas-Carr@uiowa.edu

\section{ABSTRACT}

Objectives: To test the efficacy of a multicomponent technology intervention for reducing daily sedentary time and improving cardiometabolic disease risk among sedentary, overweight university employees.

Design: Blinded, randomised controlled trial.

Setting: A large south-eastern university in the USA. Participants: 49 middle-aged, primarily female, sedentary and overweight adults working in sedentary jobs enrolled in the study. A total of 40 participants completed the study.

Interventions: Participants were randomised to either: (1) an intervention group ( $N=23 ; 47.6+9.9$ years; $94.1 \%$ female; $\left.33.2+4.5 \mathrm{~kg} / \mathrm{m}^{2}\right)$; (2) or wait-list control group ( $\mathrm{N}=17 ; 42.6+8.9$ years; $86.9 \%$ female; 31.7 $+4.9 \mathrm{~kg} / \mathrm{m}^{2}$ ). The intervention group received a theorybased, internet-delivered programme, a portable pedal machine at work and a pedometer for 12 weeks. The wait-list control group maintained their behaviours for 12 weeks.

Outcome measures: Primary (sedentary and physical activity behaviour measured objectively through StepWatch) and secondary (heart rate, blood pressure, height, weight, waist circumference, per cent body fat, cardiorespiratory fitness, fasting lipids) outcomes were measured at baseline and postintervention (12 weeks). Exploratory outcomes including intervention compliance and process evaluation measures were also assessed postintervention.

Results: Compared to controls, the intervention group reduced daily sedentary time (mean change $(95 \% \mathrm{Cl})$ : $-58.7 \mathrm{~min} /$ day $(-118.4$ to $0.99 ; p<0.01))$ after adjusting for baseline values and monitor wear time. Intervention participants logged on to the website $71.3 \%$ of all intervention days, used the pedal machine $37.7 \%$ of all working intervention days and pedalled an average of $31.1 \mathrm{~min} /$ day.

Conclusions: These findings suggest that the intervention was engaging and resulted in reductions in daily sedentary time among full-time sedentary employees. These findings hold public health significance due to the growing number of sedentary jobs and the potential of these technologies in largescale worksite programmes.

Trial Registration: ClinicalTrials.gov \#NCT01371084.

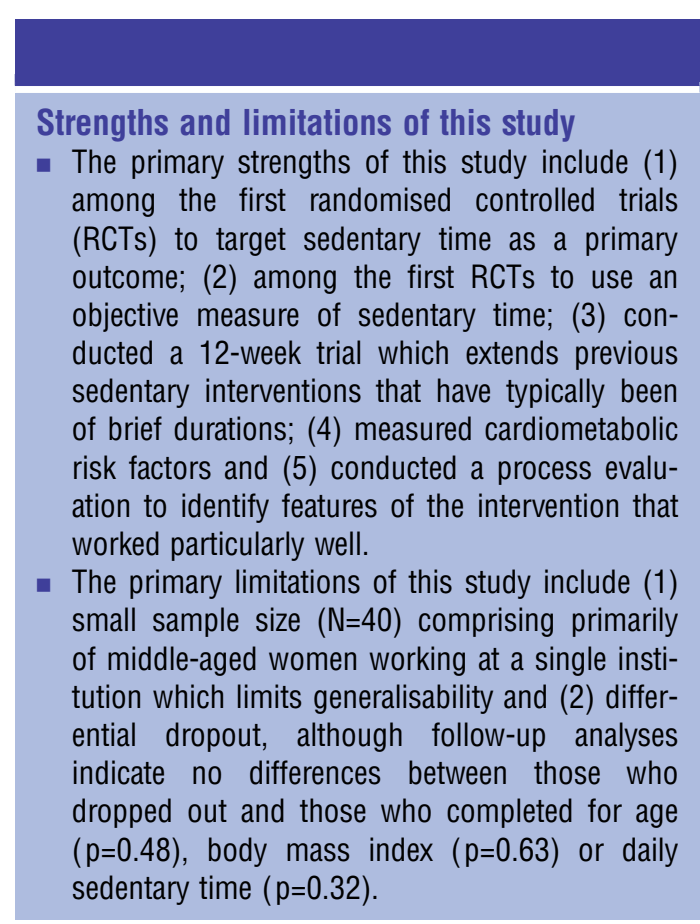

\section{INTRODUCTION}

Excessive time spent in sedentary behaviour is an independent risk factor for multiple chronic health outcomes including cardiovascular disease, ${ }^{1}{ }^{2}$ type 2 diabetes, ${ }^{3}$ hypertension, ${ }^{4}$ metabolic syndrome ${ }^{5}$ and obesity. ${ }^{6}$ Conversely, recent acute experimental studies suggest that interrupting and/or replacing excessive sedentary behaviour with light intensity physical activity throughout the day may be effective for improving various cardiometabolic disease risk factors. ${ }^{7}$ The modern workplace has been identified as a setting in which individuals engage in prolonged bouts of sedentary time. ${ }^{9}$ Adults working in fulltime sedentary jobs are at particular risk of being sedentary as they often spend more than $75 \%$ of their work time sitting. ${ }^{9-11}$ Currently, more than $27 \%$ of the US labour force works in low-activity occupations. ${ }^{12}$ The observed decline in occupational energy 
expenditure ( $100 \mathrm{kcal} /$ day $)$ over the past 50 years has been identified as a key contributor to the observed increase in mean body mass among US adults over the same time period. ${ }^{13}$ Traditional, behaviourally focused worksite interventions have focused primarily on increasing physical activity and resulted in modest effect sizes (Cohen's d=0.21-0.22). ${ }^{14}{ }^{15}$ In a shift away from behaviourally focused approaches, studies grounded in social ecological theory ${ }^{16}$ have begun testing the effect of modifying the work environment to reduce occupational sedentary time.

Until now, only a handful of sedentary interventions have been conducted in the worksite. While many early worksite sedentary interventions did not demonstrate effectiveness, ${ }^{17}$ recent trials have shown promise for reducing sitting time. ${ }^{18-20}$ Overall, many sedentary intervention studies conducted in the worksite have been limited by the use of self-report measures of sedentary time and/or short-duration interventions (1-4 weeks). Further, most studies in this area have promoted reduced 'sitting time'. Given the recent availability of seated activity permissive workstations ${ }^{10}$ and the possible desire/need of many employers and employees to remain seated while completing their work, there is a need for interventions that promote 'active sitting' as opposed to 'reduced sitting' as a means for reducing sedentary time.

In a previous study testing the feasibility of modifying the work environment as a means of reducing occupational sedentary time through promoting active sitting, our team provided portable pedal machines (MagneTrainer, 3D Innovations) to 18 sedentary desk workers for 4 weeks. ${ }^{10}$ Importantly, participants rated the pedal machines as feasible and acceptable for use while completing their work. Further, despite a lack of any accompanying behavioural intervention, participants used the pedal machines on $61 \%$ of all workdays for an average of $23.4 \mathrm{~min} /$ day. Although these results are promising, it is possible that the addition of a motivational behavioural intervention could result in increased pedalling compliance and reduced sedentary time.

The primary aim of the present study was to test the effectiveness of a multicomponent intervention for reducing daily sedentary time among a sample of sedentary, overweight, full-time working adults compared to a wait-list control group. We hypothesised that the intervention group would significantly reduce daily sedentary time compared to the wait-list control group after 12 weeks. As a secondary aim, we tested the effectiveness of intervention on cardiometabolic risk factors including measures of adiposity, blood pressure, estimated aerobic fitness and blood lipids. We hypothesised that the intervention group would reduce their overall cardiometabolic disease risk compared to the wait-list control group. Finally, as an exploratory aim, we conducted a process evaluation to explore intervention compliance and identify helpful components of the intervention.

\section{METHODS}

\section{Subjects and design}

Many sedentary interventions until now have been limited by short durations. Therefore, we conducted a 12-week randomised controlled trial design comparing a treatment group to a no treatment wait-list control group. We recruited apparently healthy but physically inactive (self-reporting less than $60 \mathrm{~min}$ of moderateto-vigorous intensity physical activity per week), overweight (body mass index (BMI) $\geq 25 \mathrm{~kg} / \mathrm{m}^{2}$ ) adults working in full-time (reporting a minimum of $35+$ $\mathrm{h} /$ week) sedentary/desk-dependent occupations (reporting a minimum of $75 \%$ of their working time spent sitting). Participants were required to gain permission from their supervisor prior to enrolment. Research staff members screened participants for eligibility by telephone. Exclusionary criteria included: (1) limitations with or contraindications to ambulatory exercise; (2) acute illness or injury; (3) cognitive impairment, psychosis or other diagnosed psychological illness (with the exception of depression and anxiety); (4) currently using psychotropic drugs or (5) diagnosis of a chronic condition such as heart failure or cancer. Participants were not compensated for participation in the study. Experimental protocols were approved by the University and Medical Center Institutional Review Board and voluntary written informed consent was obtained from each participant.

Participants of all races and ethnic backgrounds working at a large southern university were passively recruited through email advertisements placed on an electronic mailing list serve that served 5392 employees. A total of 192 people responded to our advertisements of which 143 were excluded from participation due to their not meeting the eligibility criteria, which primarily consisted of not meeting BMI and/or physical activity requirements $(\mathrm{N}=120)$; declining to participate $(\mathrm{N}=19)$ or other reasons $(\mathrm{N}=4)$. A $1: 1$ random allocation sequence was generated by the principal investigator using an online random sequence generator. ${ }^{21}$ Participants were assigned to one of two groups by a research staff member not involved in data collection based on the order in which they enrolled into the study. A total of 49 participants deemed interested and eligible for participation were randomised to one of the two groups: (1) intervention $(\mathrm{N}=25)$; (2) waitlist control $(\mathrm{N}=24)$. Of the 49 participants enrolled, 40 completed all baseline and postintervention assessments. Nine participants were lost to follow-up (figure 1). Final analyses were completed on 40 participants with 23 intervention participants and 17 control participants (table 1). More than half of all participants were college educated, reported an annual income greater than $\$ 40000$ and reported being non-Hispanic/White. Participants were enrolled and completed all testing sessions between June 2011 and June 2012. 


\section{CONSORT Flow Diagram}

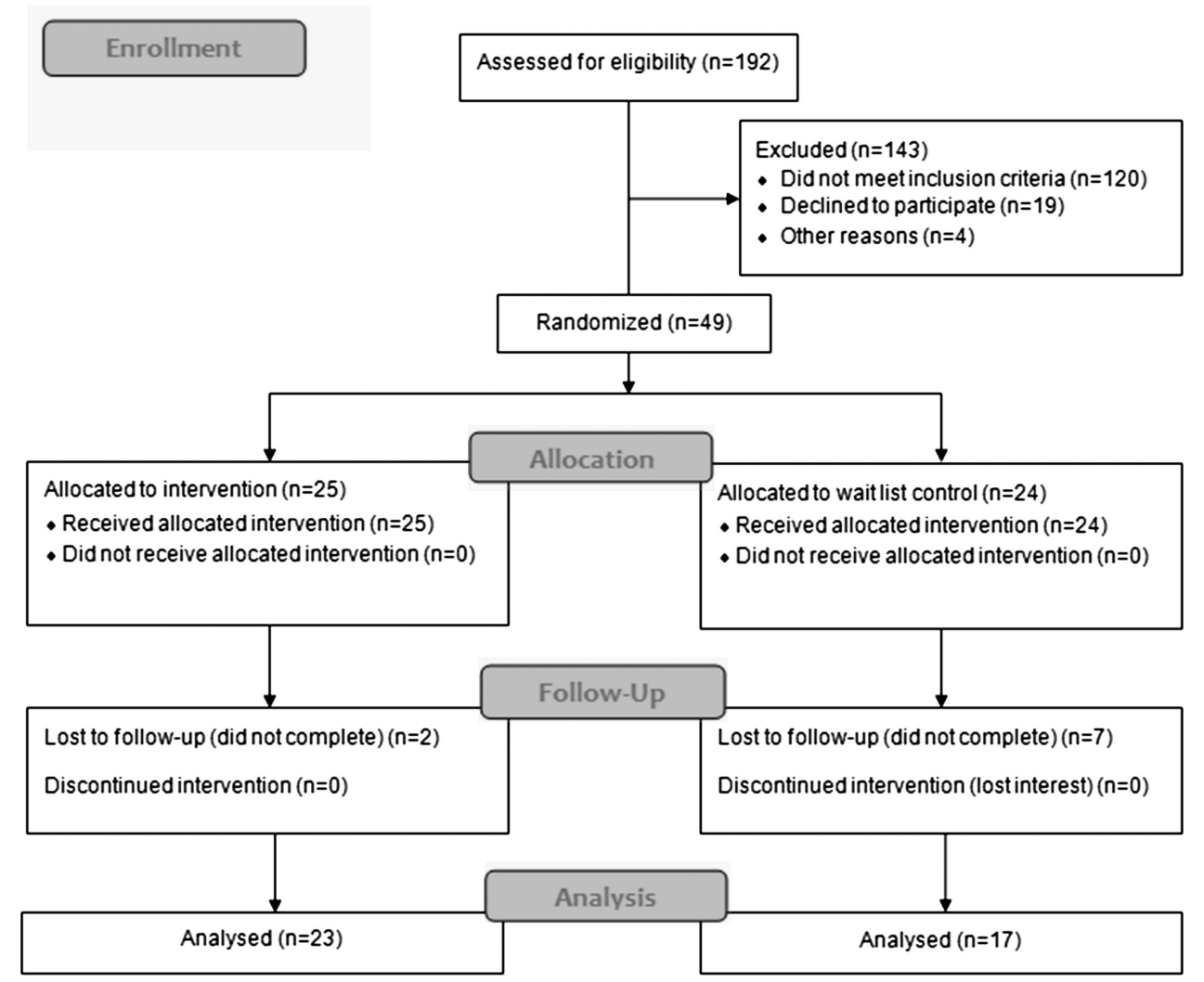

Figure 1 Sequence of events and recruitment/enrolment schematic. Study was coordinated at East Carolina University, Greenville, North Carolina, from June 2011 to June 2012.

\section{Group descriptions}

Wait-list control group

Participants randomised to the wait-list control group were asked to maintain their current behaviours for 12 weeks at which time they were given the option to receive the intervention treatment materials.

\section{Intervention group}

The primary intent of the intervention was to encourage participants to reduce their time spent sedentary. The name used to promote the study on advertisements and study materials was "Pedal@Work: Reducing time spent sedentary..." The intervention (figure 2) comprised three primary components: (1) access to a portable pedal machine (MagneTrainer, 3D Innovations, Greeley, Colorado, USA) at their worksite; (2) access to a motivational website (Walker Tracker, Portland, Oregon, USA) to receive tips and reminders focused on reducing sedentary behaviours throughout the day and (3) a pedometer to use in conjunction with the website (Omron

Table 1 Baseline characteristics by group mean+SD $(\mathrm{N}=40)$

\begin{tabular}{llll} 
& Control group (N=17) & Intervention group (N=23) & All (N=40) \\
\hline Age (years) & $47.6(9.9)$ & $42.6(8.9)$ & $44.7(9.6)$ \\
Female (\%) & 94.1 & 86.9 & 90.0 \\
Height (inch) & $65.2(3.2)$ & $65.4(3.4)$ & $65.4(3.4)$ \\
Weight (Ibs) & $201.3(30.2)$ & $194.1(34.9)$ & $197.2(32.8)$ \\
Body mass index & $33.2(4.5)$ & $31.7(4.9)$ & $32.4(4.8)$ \\
Non-Hispanic White (\%) & 76.5 & 63.6 & 70.0 \\
College graduate (\%) & 71.0 & 86.0 & 78.5 \\
Income $>$ \$0 000 (\%) & 62.5 & 63.6 & 63.0 \\
Job category (\%) & & & \\
$\quad$ Professional/executive & 35.0 & 52.0 & 45.0 \\
$\quad$ Administrative & 65.0 & 48.0 & 55.0 \\
\hline
\end{tabular}


$\mathrm{HJ}-150)$. The pedal machine is a portable (18" height, $20^{\prime \prime}$ length) device that has been demonstrated as acceptable for use during sedentary office work. ${ }^{10}$ Because participants were sedentary employees working in professional environments, the rationale for providing them pedal machines at work was to allow them to engage in light-intensity activity (ie, active sitting) that they could perform for long periods throughout the day without causing them to perspire. The pedal machine is accompanied by a PC interface and software package that allows for objective monitoring of individual pedal activity. This software also provides the user with realtime feedback through a display monitor on pedal time, distance, speed and caloric expenditure. The research team delivered the pedal machine to each participant's worksite, downloaded the pedal tracking software to the participant's work computer and worked with the participant to identify the most feasible set-up. Intervention participants were asked to keep the pedal machine connected to their PC during all working hours. Intervention participants were required to gain clearance to use the pedal machines and software at their work prior to participation. No additional interaction between the research staff and participant's supervisors occurred during the course of the study. Participants were located in 18 different buildings across the campus. No participants worked within visible proximity of each other.
Intervention participants were also provided access to a motivational website that was individually customised to the local culture of the worksite of the participants who were recruited (figure 2). Examples of customisation included posting local images and messages specific to the local institution. The content of the intervention focused primarily on reducing time spent sedentary (both increasing active sitting through pedalling and taking breaks from sitting). Example messages included "Let's try to pedal an extra 5 min during your lunch break today" and "Did you know standing up burns more calories than sitting? Maybe it's time for a break!?" Most messages targeted time spent at work, although some messages broadly targeted sedentary time in general and could have impacted sedentary time outside work. Messages were theory-based targeting constructs of the Social Cognitive Theory ${ }^{22}$ including self-monitoring, social support, self-efficacy and perceived environment. For example, participants were prompted through daily email messages to self-monitor their daily pedal time and daily steps (through a pedometer) on the website. The activity participants logged on the website was used to fuel a virtual competition (aimed at building social support) in which small groups of intervention participants (4-5 per group) collectively travelled across the USA. Participants were also emailed three theory-based motivational messages each week targeting goal setting, self-efficacy and perceived environment. Specific goals

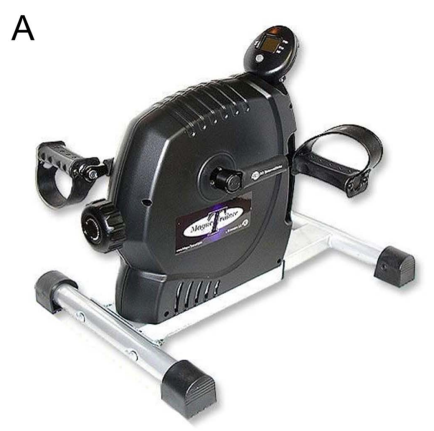

B

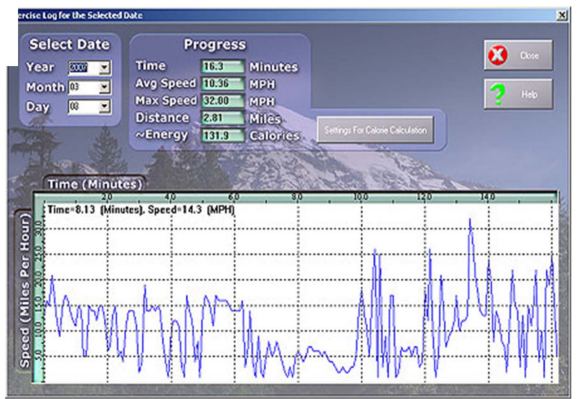

C Reset Time: 00:01:06 Distance: 0.23 Calories: 8.2

E

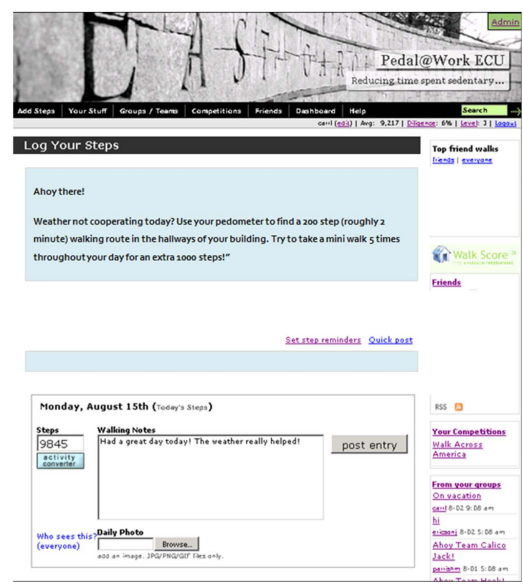

Figure 2 Images of intervention features: (A) portable pedal machine, (B) pedal machine activity tracking software screenshot, (C) pedal machine monitor feedback, (D) pedometer and (E) screenshot of the website homepage. 
were not set for intervention participants; rather, participants received advice on how to set goals and suggestions for daily pedalling time (eg, "Try fitting in $10 \mathrm{~min}$ of pedalling during your lunch today."). Finally, using a forum similar to Facebook, participants were able to post profile photos and status updates on a newsfeed and send messages to members of their small groups further fostering social support.

\section{Measures}

All measures were collected at baseline and postintervention (12 weeks) in a controlled laboratory setting by two staff members blinded to the participant's group assignment. The two staff members were provided specific measurement duties to ensure that each measure was collected by the same staff member at baseline and postintervention. The primary outcome was daily sedentary time as measured objectively by the StepWatch physical activity monitor (Orthocare Innovations, Mountlake Terrace, Washington, USA). The StepWatch was specifically chosen for this study as it is worn on the ankle, making it ideally suited for measuring pedalling and walking behaviour. Further, the StepWatch has been demonstrated as a reliable measure of walking behaviour (3 day agreements for steps per day $(39.1 \%$ ) and per cent inactive time $(9.52 \%))^{23}$ and an accurate measure of sedentary behaviours (89.8-99.5\% accurate) and light intensity walking $(86.1 \%$ accurate $){ }^{24}$ The StepWatch has demonstrated superior ability for detecting pedalling time (23.5-54.4\% accurate) when compared to hip-worn accelerometers $\left(8.1-47.1 \%\right.$ correct).$^{25}$ Participants were asked to wear the monitor during all wakeful hours for seven consecutive days and keep track of wear time using an activity log. Days on which participants wore the monitors for less than $10 \mathrm{~h}$ were excluded from the final analysis. The threshold for sedentary (0 steps/min) was based on the recommendation provided by the product manufacturer. The thresholds for light (1-45 steps $/ \mathrm{min})$, moderate (46-75 steps/min) and vigorous (76+ steps/ min) intensity physical activities were based on previous work which demonstrated a moderate-intensity walking stride rate to range from 90 to 113 steps/min depending on the height and stride length. ${ }^{26}$

Blood pressure was measured with a stethoscope and sphygmomanometer using standard techniques. Heart rate was monitored with a Polar heart rate monitor and chest strap. Body mass was measured to the nearest $0.1 \mathrm{~kg}$ and height to the nearest $0.5 \mathrm{~cm}$ using a professional grade digital medical scale and height rod (Seca 769, Hanover, Maryland, USA). Waist circumference was measured in duplicate with a standard Gulick measuring tape according to standard procedures. ${ }^{27}$ Fasting blood lipids (total cholesterol, low-density lipoprotein cholesterol, high-density lipoprotein (HDL) cholesterol and triglycerides) were assessed using a finger stick and a point-of-care analyser (Cholestech LDX analyzer) which has previously been demonstrated as an accurate and precise measure of total cholesterol $(1.6 \%$ and $3 \%$, respectively),
HDL-cholesterol $(-2.74 \%$ and $1.05 \%$, respectively) and triglycerides $\left(2.11 \%\right.$ and $2.65 \%$, respectively). ${ }^{28}$ Estimated aerobic fitness was assessed through a singlestage submaximal treadmill walking test which has previously been demonstrated as a valid estimate of total aerobic fitness among middle-aged adults. ${ }^{29}$

Compliance with the pedal machine (ie, minutes pedalled/day, total days pedalled) was assessed objectively through the activity tracking software. Pedal compliance data were downloaded directly from each individual's work computer at the end of 12 weeks. Website use compliance (eg, number of website logins, number of steps logged on the website) was assessed objectively at the end of 12 weeks through a backend tracking database made available by the website administrators. In order to assess which components of the intervention participants 'perceived' as helpful for reducing their sedentary time, a process evaluation survey was conducted at 12 weeks among intervention completers. Participants rated each intervention component using a five-point Likert scale.

\section{Design/statistical analysis}

A sample size of 40 (recruiting 49 assuming a $20 \%$ attrition) was necessary to detect, with $80 \%$ power, at $\alpha=0.05$, a $30 \mathrm{~min} /$ day difference in daily sedentary time. The $30 \mathrm{~min} /$ day difference was identified as a reasonable estimate based on our previous study in which participants used the same pedal machines an average of $23 \mathrm{~min} /$ day without any motivational intervention. ${ }^{10}$ Means (SD) were used to describe data where appropriate. This study was not powered to detect differences in the measured cardiometabolic risk factors. These measures were collected as secondary outcomes and to inform future trials.

The paired samples t test was used to determine any within-group differences at baseline and postintervention. Analysis of covariance (ANCOVA) was used to test for differences between groups at postintervention. Baseline values of interest were included as covariates in the model for all continuous variables consistent with the recommended statistical procedures. ${ }^{30}$ The underlying assumption of no between group differences at baseline was confirmed for all measures by one way ANCOVA. Finally, the $95 \%$ CI for the mean differences of all primary and secondary outcomes of interest is presented.

\section{RESULTS}

The baseline characteristics of both groups are presented in table 1. Overall, participants were middle-aged and mostly classified as obese. More than half of all participants were college educated, reported an annual income greater than $\$ 40000$ and reported being non-Hispanic/White. Differential dropout was observed over the course of the study, although sensitivity analyses indicate no differences between those who dropped out 
and those who completed the study for measures of age $(\mathrm{p}=0.48)$, BMI $(\mathrm{p}=0.63)$, or daily sedentary time $(\mathrm{p}=0.32)$.

Table 2 illustrates monitor wear time for both groups at each time point and changes in the primary outcomes of sedentary and physical activity behaviours for both groups. No between-group differences or within-group differences were observed for monitor wear time at either baseline or postintervention. No differences were observed for any sedentary or physical activity measures at baseline. A significant intervention effect favouring the intervention group (95\% CI -0.99 to $118.4 \mathrm{~min}$ / day) was observed for the absolute number of daily sedentary minutes after adjusting for baseline sedentary time and monitor wear time. Intervention effects reached near significance for both per cent daily time spent sedentary (95\% CI $-6.8 \%$ to $-0.6 \%)$ and per cent time spent in moderate intensity physical activity $(95 \%$ CI $0.0 \%$ to $2.6 \%$; see table 2 ).

Table 3 illustrates changes in the secondary outcomes of cardiometabolic risk factors for both groups. A significant intervention effect was observed for waist circumference $\mathrm{p}=0.03$ after adjusting for baseline values (table 3). No significant intervention effects were observed for any other cardiometabolic risk factors.

A total of 23 participants completed the intervention and provided compliance data (see table 4). Intervention participants logged on to the website an average of $71.3 \%$ (59.8 days) of all days they had access to the website (including weekends; table 4). Intervention participants also logged an average of 7945 +4634 steps/day on the website over 12 weeks. Participants pedalled an average of $37.7 \%$ (22.6 days) of all days they had access to the pedal machine (excluding weekends). Participants pedalled an average of 31.1 $+31.6 \mathrm{~min} /$ day on the days they used the pedal machines and an average of $16.1+17.2 \mathrm{~min} /$ pedalling bout.

When asked to rate the helpfulness of each intervention feature for reducing their sedentary time, participants rated the pedal machine biofeedback display, the pedometer and self-monitoring activity on the website as 'extremely helpful' (median Likert score $=5$; table 5).

Table 2 Absolute and relative time spent in sedentary and physical activity behaviours at baseline and postintervention for control $(\mathrm{N}=17)$ and intervention $(\mathrm{N}=23)$ participants $\dagger$

\begin{tabular}{|c|c|c|c|c|c|}
\hline & Baseline & Postintervention & $\begin{array}{l}\text { Mean difference } \\
(95 \% \mathrm{Cl})\end{array}$ & $\begin{array}{l}\text { Within-group } \\
p \text { value }\end{array}$ & $\begin{array}{l}\text { Between-group } \\
\text { p value (post) }\end{array}$ \\
\hline Monitor wear time (min/day) & & & & & 0.15 \\
\hline Control & $829.6(93.5)$ & $869.5(94.1)$ & & 0.10 & \\
\hline Intervention & $867.1(142.8)$ & $827.2(71.9)$ & & 0.42 & \\
\hline Minutes sedentary (min/day) & & & & & $0.01^{* *}$ \\
\hline Control & $544.2(76.9)$ & $599.7(106.6)$ & $+55.5(2.8$ to 108.1$)$ & $0.04^{*}$ & \\
\hline Intervention & $584.9(136.1)$ & $526.1(77.3)$ & $-58.7(-118.4$ to 0.99$)$ & $0.04^{*}$ & \\
\hline Percentage of time sedentary & & & & & 0.06 \\
\hline Control & $65.7(7.5)$ & $67.5(8.0)$ & $-1.8(-2.7$ to 6.3$)$ & 0.41 & \\
\hline Intervention & $67.6(7.2)$ & $63.9(7.9)$ & $-3.7(-6.8$ to -0.6$)$ & $0.02^{*}$ & \\
\hline Minutes light (min/day) & & & & & 0.64 \\
\hline Control & $265.7(84.0)$ & $262.2(70.8)$ & $-3.5(-45.6$ to 38.6$)$ & 0.86 & \\
\hline Intervention & $263.9(69.5)$ & $270.3(69.5)$ & $+6.4(-18.7$ to 31.5$)$ & 0.60 & \\
\hline Percentage of time light & & & & & 0.16 \\
\hline Control & $31.9(8.1)$ & $30.3(8.4)$ & $-1.6(-6.0$ to 2.8$)$ & 0.46 & \\
\hline Intervention & $30.6(8.2)$ & $32.7(7.6)$ & $2.1(-0.8$ to 4.9$)$ & 0.15 & \\
\hline Minutes moderate (min/day) & & & & & 0.13 \\
\hline Control & $18.6(25.2)$ & $17.4(23.7)$ & $-1.2(-4.9$ to 2.4$)$ & 0.50 & \\
\hline Intervention & $14.5(18.5)$ & $23.3(28.0)$ & $+8.8(-1.6$ to 19.2$)$ & 0.09 & \\
\hline Percentage of time moderate & & & & & 0.06 \\
\hline Control & $2.3(3.2)$ & $2.0(2.9)$ & $-0.3(-0.7$ to 0.2$)$ & 0.21 & \\
\hline Intervention & $1.5(1.5)$ & $2.8(3.4)$ & $+1.3(0.0$ to 2.6$)$ & $0.04^{*}$ & \\
\hline Minutes vigorous (min/day) & & & & & 0.33 \\
\hline Control & $1.2(2.6)$ & $1.5(2.7)$ & $+0.4(-0.2$ to 0.9$)$ & 0.19 & \\
\hline Intervention & $2.7(6.4)$ & 4.9 (10.9) & $+2.2(-2.7$ to 7.0$)$ & 0.37 & \\
\hline Percentage of time vigorous & & & & & 0.25 \\
\hline Control & $0.1(0.3)$ & $0.2(0.3)$ & $0.0(0.0$ to 0.1$)$ & 0.32 & \\
\hline Intervention & $0.3(0.6)$ & $0.6(1.3)$ & $+0.3(-0.3$ to 0.9$)$ & 0.26 & \\
\hline
\end{tabular}


Table 3 Cardiometabolic risk factors at baseline and postintervention for control $(\mathrm{N}=17)$ and intervention ( $\mathrm{N}=23)$ participants

\begin{tabular}{|c|c|c|c|c|c|}
\hline & Baseline & Postintervention & $\begin{array}{l}\text { Mean difference } \\
(95 \% \mathrm{Cl})\end{array}$ & $\begin{array}{l}\text { Within-group } \\
p \text { value }\end{array}$ & $\begin{array}{l}\text { Between-group } \\
\text { p value (post) }\end{array}$ \\
\hline Weight (lbs) & & & & & 0.58 \\
\hline Control & $201.4(30.2)$ & $202.4(30.5)$ & $+1.0(-1.0$ to 3.0$)$ & 0.31 & \\
\hline Intervention & $194.2(34.9)$ & $194.4(34.5)$ & $+0.2(-2.3$ to 2.7$)$ & 0.86 & \\
\hline BMI $\left(\mathrm{kg} / \mathrm{m}^{2}\right)$ & & & & & 0.76 \\
\hline Control & $33.2(4.5)$ & $33.4(4.6)$ & $+0.2(-0.1$ to 0.5$)$ & 0.21 & \\
\hline Intervention & $31.8(5.0)$ & $31.9(5.0)$ & $-0.1(-0.3$ to 0.5$)$ & 0.57 & \\
\hline Systolic BP (mm Hg) & & & & & 0.70 \\
\hline Control & $117.1(13.0)$ & $117.5(12.8)$ & $-0.8(-5.0$ to 3.6$)$ & 0.71 & \\
\hline Intervention & $120.0(13.8)$ & $115.7(10.8)$ & $-4.3(-8.0$ to -0.7$)$ & $0.02^{*}$ & \\
\hline Diastolic BP (mm Hg) & & & & & 0.51 \\
\hline Control & $72.8(10.3)$ & $73.2(10.6)$ & $-0.1(-5.0$ to 4.8$)$ & 0.96 & \\
\hline Intervention & $78.2(10.3)$ & $75.4(7.4)$ & $-2.8(-6.2$ to 0.7$)$ & 0.11 & \\
\hline Waist circumference $(\mathrm{cm})$ & & & & & $0.03^{* *}$ \\
\hline Control & $92.9(11.1)$ & $93.9(10.8)$ & $+1.0(-0.7$ to 2.7$)$ & 0.22 & \\
\hline Intervention & $92.6(11.2)$ & $91.6(11.3)$ & $-1.0(-2.1$ to 0.3$)$ & 0.06 & \\
\hline Estimated V02 (mL/kg/min) & & & & & 0.10 \\
\hline Control & $29.6(2.5)$ & $30.0(2.6)$ & $+0.3(-0.1$ to 0.8$)$ & 0.14 & \\
\hline Intervention & $30.8(5.1)$ & $31.1(4.6)$ & $+0.3(-0.6$ to 1.1$)$ & 0.53 & \\
\hline Total cholesterol (mg/dL) & & & & & 0.83 \\
\hline Control & $184.4(25.9)$ & $185.0(18.9)$ & $-0.8(-15.1$ to 13.4$)$ & 0.91 & \\
\hline Intervention & $191.4(26.3)$ & $189.7(27.0)$ & $+0.7(-5.9$ to 7.2$)$ & 0.83 & \\
\hline HDL (mg/dL) & & & & & 0.65 \\
\hline Control & $47.6(18.4)$ & 46.7 (18.9) & $-0.9(-6.8$ to 5.1$)$ & 0.76 & \\
\hline Intervention & $45.7(17.6)$ & $43.7(16.4)$ & $-2.1(-8.1$ to 3.4$)$ & 0.46 & \\
\hline LDL (mg/dL) & & & & & 0.96 \\
\hline Control & $111.2(32.1)$ & $120.2(25.3)$ & $+5.4(-11.3$ to 22.1$)$ & 0.50 & \\
\hline Intervention & $119.4(23.2)$ & $116.7(29.4)$ & $-3.7(-12.8$ to 5.4$)$ & 0.41 & \\
\hline Triglycerides & & & & & 0.91 \\
\hline Control & $130.6(65.4)$ & $131.0(59.9)$ & $+4.7(-24.0$ to 33.3$)$ & 0.73 & \\
\hline Intervention & $98.4(45.2)$ & $118.4(57.3)$ & $+18.3(-0.1$ to 36.7$)$ & 0.05 & \\
\hline
\end{tabular}

Participants rated the email reminders to log daily activity and access to the pedal machine as 'quite helpful' (median Likert score $=4.0$; table 5).

\section{DISCUSSION}

The primary findings of this study suggest that this multicomponent intervention resulted in significant time spent sedentary in a small sample of inactive, overweight employees. The decreased sedentary time observed among the intervention group appears to have been at least partially replaced by an increase in moderate intensity activity. Our findings are important as the present study was among the first worksite interventions to promote 'active sitting' as a means of reducing sedentary time. Further, the present study was conducted over a longer duration (12 weeks) compared to similar trials, ${ }^{19} 31$ which is necessary in order to determine whether the intervention instils habitual behaviour change and/or whether such behaviour change results in changes in cardiometabolic outcomes. While longer trials are necessary to confirm whether sedentary employees will adhere to such an intervention, process evaluation data suggest that participants engaged with the intervention and maintained engagement through 12 weeks. This study also utilised an objective measure of sedentary/physical activity behaviour, whereas many previous interventions have relied on self-report measures of sedentary time. ${ }^{17}$ The present study builds on past studies as our study was among the first to demonstrate significant reductions in objectively measured sedentary time when compared to a control group. This is important, as it has been suggested that decreasing sedentary time can result in improved health benefits independent of physical activity. ${ }^{2}$ 32-34

Sedentary time among the intervention group was reduced by an average of $58 \mathrm{~min} /$ day or $3.7 \%$ of daily time. Our findings are within the range of similar studies. For example, Kozy-Keadle $e t a \ell^{31}$ found that daily sedentary time reduced from $67 \%$ to $62.7 \%$ after a simple 7-day intervention that included educational materials on sedentary health risks and tips to reduce 
Table 4 Intervention compliance measures among intervention completers $(\mathrm{N}=23)$

\begin{tabular}{lll}
\hline & $\begin{array}{l}\text { Mean/per } \\
\text { cent }\end{array}$ & SD \\
\hline Web compliance \% (days logged & 71.3 & 35.7 \\
in/days with access) & & \\
Average steps logged per day & 7945 & 4634 \\
Average days pedalled over 12 weeks & 22.6 & 17.6 \\
Pedal compliance \% (days pedalled/ & 37.7 & 29.3 \\
days with access) & & \\
Average pedal bouts/day & 1.9 & 0.9 \\
Average minutes pedalled/day used & 31.1 & 31.6 \\
Average minutes pedalled/pedal bout & 16.1 & 17.2 \\
\hline
\end{tabular}

sedentary time. However, this study did not include a control group. In a study that did include a control group, Evans et $a l^{19}$ found no between-group differences in objectively measured sitting time after 5 days of point-of-choice software reminders to stand up every 30 min while at work.

We also observed a significant intervention effect for waist circumference. This finding is important as waist circumference has been shown to predict mortality among adults with coronary artery disease. ${ }^{35}$ Confidence in this finding is strengthened by past studies that have found waist circumference to be sensitive to change in the absence of changes in other measures of adiposity ${ }^{36}$ as well as studies reporting interruptions from sedentary time to be associated with waist circumference. ${ }^{37}$ Furthermore, this finding is consistent with the findings of a previous 16-week internet-delivered physical activity programme which demonstrated modest improvements in daily steps and waist circumference. ${ }^{36}$ The lack of changes in other cardiometabolic risk factors may be due to the low intensity of the intervention as well as the limited duration of 12 weeks. Studies of longer duration are needed to determine whether long-term reduction in sedentary time results in cardiometabolic risk reduction.

Participant compliance with the website overall was high with participants logging on to the website an average of $71 \%$ of all intervention days. This is important as past internet-delivered intervention studies have identified engagement to be a challenge ${ }^{38} 39$ and a predictor of intervention success. ${ }^{40}$ By comparison, Lewis et $a l^{41}$ reported that participants logged on to a physical activity website a median number of 50 times $(13.7 \%)$ over 12 months. The reasons for such high website compliance in the present study may be due to the tailoring of the website to include locally relevant images and messages and/or the regular email messages.

Participant compliance with the pedal machines in the present 12 week trial (31 min/day) was higher when compared to compliance in our previous 4-week trial (23 min/day). ${ }^{10}$ These findings suggest that the added motivational intervention, which included suggestions for setting goals and finding time to pedal each day, resulted in improved daily compliance that was sustained over a longer duration. Despite the logistical limitation of the portable pedal machine when paired with standard height desks (ie, many participants reported their knees hit the underside of their desk while pedalling), participants used the pedal machine on a fairly regular basis. In order to maximise compliance with such portable pedal machines in future studies, it is recommended these devices be paired with height adjustable desks that allow for comfortable pedalling during computer work tasks.

Intervention participants reported features that provided feedback including the pedal machine tracking software, pedometers and self-monitoring daily activity on the website (which was immediately followed by a graph illustrating the individual's daily progress) as the most helpful features for reducing their daily sedentary time. This information is important and could be used to inform future interventions aimed at reducing sedentary behaviour. This finding is consistent with past studies which have found biofeedback as a useful tool to improve health behaviours. ${ }^{42} 43$

The main limitation of the study was the limited generalisability due to a small sample size that primarily comprised middle-aged women working at a single institution. We also experienced differential dropout, although follow-up analyses indicate no differences

Table 5 Quartile and median Likert scale responses (1=not at all helpful; 2=a little helpful; 3=moderately helpful; 4=quite helpful; $5=$ extremely helpful) on the helpfulness of individual intervention components for reducing sedentary time ( $\mathrm{N}=23$ )

\begin{tabular}{|c|c|c|c|}
\hline \multirow{2}{*}{$\begin{array}{l}\text { Please rate how helpful each of the following intervention components was in reducing } \\
\text { your daily sedentary time }\end{array}$} & \multicolumn{3}{|c|}{ Likert scale } \\
\hline & $\overline{\text { Q1 }}$ & Median & Q3 \\
\hline Pedal machine biofeedback display (minutes pedalled, calories burned, etc) & 4 & 5 & 5 \\
\hline Wearing the pedometer & 4 & 5 & 5 \\
\hline Self-monitoring daily steps and pedal time on the website & 4 & 5 & 5 \\
\hline Email reminders to log physical activity on website & 4 & 4 & 5 \\
\hline Access to pedal exercise machine at work & 4 & 4 & 5 \\
\hline 'Walk Across America' group challenge on website & 3 & 3 & 5 \\
\hline Social networking features on website (profile, newsfeed, messaging) & 3 & 3 & 4 \\
\hline Environmental features (Walkscore, information on facilities) & 3 & 3 & 4 \\
\hline
\end{tabular}


between those who dropped out and those who completed for age, BMI or daily sedentary time.

The present study is among the first interventions conducted within the worksite aimed specifically at reducing daily sedentary time to demonstrate between-group differences in objectively measured sedentary time. Compliance with the motivational website was high while compliance with the pedal machine was moderate. These findings are promising, considering the relatively low cost of the intervention at $\$ 180$ (pedal machine and software, pedometer, access to website) per participant. While an intervention effect was observed for waist circumference, no between-group differences were observed for any other cardiometabolic risk factors. More sedentary focused interventions are needed to examine whether reducing sedentary time can be sustained in the long term and whether long-term changes result in significant reductions in risk for chronic diseases.

Contributors LJC was responsible for the design of the study and led the manuscript preparation. KK assisted in the design of the study and also in manuscript preparation. MP contributed to the manuscript preparation and was solely responsible for leading the intervention which included duties of interacting with participants on a daily basis. RS and KC contributed to the manuscript preparation and were also responsible for collecting data at the baseline and postintervention time points.

Funding This study was funded by Oak Ridge Associated Universities grant \#212112.

\section{Competing interests None.}

Ethics approval University and Medical Center Institutional Review Board of East Carolina University.

Provenance and peer review Not commissioned; externally peer reviewed.

Data sharing statement No additional data are available.

Open Access This is an Open Access article distributed in accordance with the Creative Commons Attribution Non Commercial (CC BY-NC 3.0) license, which permits others to distribute, remix, adapt, build upon this work noncommercially, and license their derivative works on different terms, provided the original work is properly cited and the use is non-commercial. See: http:// creativecommons.org/licenses/by-nc/3.0/

\section{REFERENCES}

1. Warren TY, Barry V, Hooker SP, et al. Sedentary behaviors increase risk of cardiovascular disease mortality in men. Med Sci Sports Exerc 2010;42:879-85.

2. Thorp AA, Healy GN, Owen N, et al. Deleterious associations of sitting time and television viewing time with cardiometabolic risk biomarkers: Australian Diabetes, Obesity and Lifestyle (AusDiab) study 2004-2005. Diabetes Care 2010;33:327-34.

3. Roberts CK, Vaziri ND, Sindhu RK, et al. A high-fat, refinedcarbohydrate diet affects renal NO synthase protein expression and salt sensitivity. J Appl Physiol 2003;94:941-6.

4. Beunza JJ, Martinez-Gonzalez MA, Ebrahim S, et al. Sedentary behaviors and the risk of incident hypertension: the SUN Cohort. Am J Hypertens 2007;20:1156-62.

5. Ford ES, Kohl HW III, Mokdad AH, et al. Sedentary behavior, physical activity, and the metabolic syndrome among U.S. adults. Obesity Res 2005;13:608-14.

6. Must A, Tybor DJ. Physical activity and sedentary behavior: a review of longitudinal studies of weight and adiposity in youth. Int $J$ Obes (Lond) 2005;29(Suppl 2):S84-96.

7. Dunstan DW, Kingwell BA, Larsen R, et al. Breaking up prolonged sitting reduces postprandial glucose and insulin responses. Diabetes Care 2012;35:976-83.

8. Duvivier BM, Schaper NC, Bremers MA, et al. Minimal intensity physical activity (standing and walking) of longer duration improves insulin action and plasma lipids more than shorter periods of moderate to vigorous exercise (cycling) in sedentary subjects when energy expenditure is comparable. PLoS ONE 2013;8:e55542.

9. Thorp AA, Healy GN, Winkler E, et al. Prolonged sedentary time and physical activity in workplace and non-work contexts: a cross-sectional study of office, customer service and call centre employees. Int J Behav Nutr Phys Act 2012;9:128.

10. Carr LJ, Walaska KA, Marcus BH. Feasibility of a portable pedal exercise machine for reducing sedentary time in the workplace. $\mathrm{Br} J$ Sports Med 2012;46:430-5.

11. McCrady SK, Levine JA. Sedentariness at work: how much do we really sit? Obesity (Silver Spring) 2009;17:2103-5.

12. Brownson RC, Boehmer TK, Luke DA. Declining rates of physical activity in the United States: what are the contributors? Annu Rev Public Health 2005;26:421-43.

13. Church TS, Thomas DM, Tudor-Locke C, et al. Trends over 5 decades in U.S. occupation-related physical activity and their associations with obesity. PLOS ONE 2011;6:e19657.

14. Conn VS, Hafdahl AR, Cooper PS, et al. Meta-analysis of workplace physical activity interventions. Am J Prev Med 2009;37:330-9.

15. Dishman RK, Oldenburg B, O'Neal H, et al. Worksite physical activity interventions. Am J Prev Med 1998;15:344-61.

16. Stokols D, Pelletier KR, Fielding JE. The ecology of work and health: research and policy directions for the promotion of employee health. Health Educ Q 1996;23:137-58.

17. Chau JY, der Ploeg HP, van Uffelen JG, et al. Are workplace interventions to reduce sitting effective? A systematic review. Prev Med 2010:51:352-6.

18. Healy GN, Eakin EG, Lamontagne AD, et al. Reducing sitting time in office workers: short-term efficacy of a multicomponent intervention. Prev Med 2013;57:43-8.

19. Evans RE, Fawole HO, Sheriff SA, et al. Point-of-choice prompts to reduce sitting time at work: a randomized trial. Am J Prev Med 2012;43:293-7.

20. Alkhajah TA, Reeves MM, Eakin EG, et al. Sit-stand workstations: a pilot intervention to reduce office sitting time. Am J Prev Med 2012;43:298-303.

21. Random.org. Random Sequence Generator. Secondary Random Sequence Generator. 2011. http://www.random.org/sequences/

22. Bandura A. ed. Social foundations of thought and action: a social cognitive theory. EnglewoodCliffs, NJ: Prentice-Hall, 1986.

23. Mudge S, Taylor D, Chang O, et al. Test-retest reliability of the StepWatch Activity Monitor outputs in healthy adults. J Phys Act Health 2010;7:671-6.

24. Foster RC, Lanningham-Foster LM, Manohar C, et al. Precision and accuracy of an ankle-worn accelerometer-based pedometer in step counting and energy expenditure. Prev Med 2005;41:778-83.

25. Carr LJ, Mahar MT. Accuracy of intensity and inclinometer output of three activity monitors for identification of sedentary behavior and light-intensity activity. J Obes 2012;2012:1-9.

26. Rowe DA, Welk GJ, Heil DP, et al. Stride rate recommendations for moderate-intensity walking. Med Sci Sports Exerc 2011;43:312-18.

27. ACSM. ACSM's guidelines for exercise testing and prescription. 7th edn. Lippincott Williams \& Wilkins, 2006.

28. Issa JS, Strunz C, Giannini SD, et al. Precision and accuracy of blood lipid analyses by a portable device (Cholestech-LDX). Arq Bras Cardiol 1996;66:339-42.

29. Ebbeling CB, Ward A, Puleo EM, et al. Development of a single-stage submaximal treadmill walking test. Med Sci Sports Exerc 1991;8:966-73.

30. Van Breukelen GJ. ANCOVA versus change from baseline: more power in randomized studies, more bias in nonrandomized studies [corrected]. J Clin Epidemiol 2006;59:920-5.

31. Kozey-Keadle S, Libertine A, Staudenmayer J, et al. The Feasibility of reducing and measuring sedentary time among overweight, non-exercising office workers. J Obes 2012;2012:1-10.

32. Owen N, Sparling PB, Healy GN, et al. Sedentary behavior: emerging evidence for a new health risk. Mayo Clin Proc 2010;85:1138-41.

33. Rhodes RE, Mark RS, Temmel CP. Adult sedentary behavior: a systematic review. Am J Prev Med 2012;42:e3-28.

34. Thorp AA, Owen N, Neuhaus M, et al. Sedentary behaviors and subsequent health outcomes in adults a systematic review of longitudinal studies, 1996-2011. Am J Prev Med 2011;41:207-15.

35. Coutinho T, Goel K, Correa de Sa D, et al. Combining body mass index with measures of central obesity in the assessment of mortality in subjects with coronary disease: role of 'normal weight central obesity'. J Am Coll Cardiol 2013;61:553-60.

36. Carr LJ, Bartee RT, Dorozynski C, et al. Internet-delivered behavior change program increases physical activity and improves cardiometabolic disease risk factors in sedentary adults: results of a randomized controlled trial. Prev Med 2008;46:431-8. 
37. Healy GN, Dunstan DW, Salmon J, et al. Breaks in sedentary time: beneficial associations with metabolic risk. Diabetes Care 2008;31:661-6.

38. Spittaels H, De Bourdeaudhuij I, Vandelanotte C. Evaluation of a website-delivered computer-tailored intervention for increasing physical activity in the general population. Prev Med 2007;44:209-17.

39. Vandelanotte C, Spathonis KM, Eakin EG, et al. Website-delivered physical activity interventions a review of the literature. Am J Prev Med 2007;33:54-64.

40. van den Berg MH, Ronday HK, Peeters AJ, et al. Engagement and satisfaction with an internet-based physical activity intervention in patients with rheumatoid arthritis. Rheumatology (Oxford) 2007;46:545-52.

41. Lewis B, Williams D, Dunsiger S, et al. User attitudes towards physical activity websites in a randomized controlled trial. Prev Med 2008;47:508-13.

42. Proper $\mathrm{KI}$, van der Beek AJ, Hildebrandt $\mathrm{VH}$, et al. Short term effect of feedback on fitness and health measurements on self reported appraisal of the stage of change. Br J Sports Med 2003;37:529-34.

43. Bravata DM, Smith-Spangler C, Sundaram V, et al. Using pedometers to increase physical activity and improve health: a systematic review. JAMA 2007;298:2296-304. 